\title{
ANALISIS USABILITY APLIKASI AUGMENTED REALITY PROCEDURE MESIN WAFER MOUNTING DI TEACHING FACTORY MANUFACTURE OF ELECTRONICS (TFME) POLITEKNIK NEGERI BATAM
}

Faradina Perdana Jodanayang ${ }^{1}$ Riwinoto $^{2}$

* Jurusan Teknik Informatika, Politeknik Negeri Batam

** Program Studi Teknik Multimedia dan Jaringan, Politeknik Negeri Batam

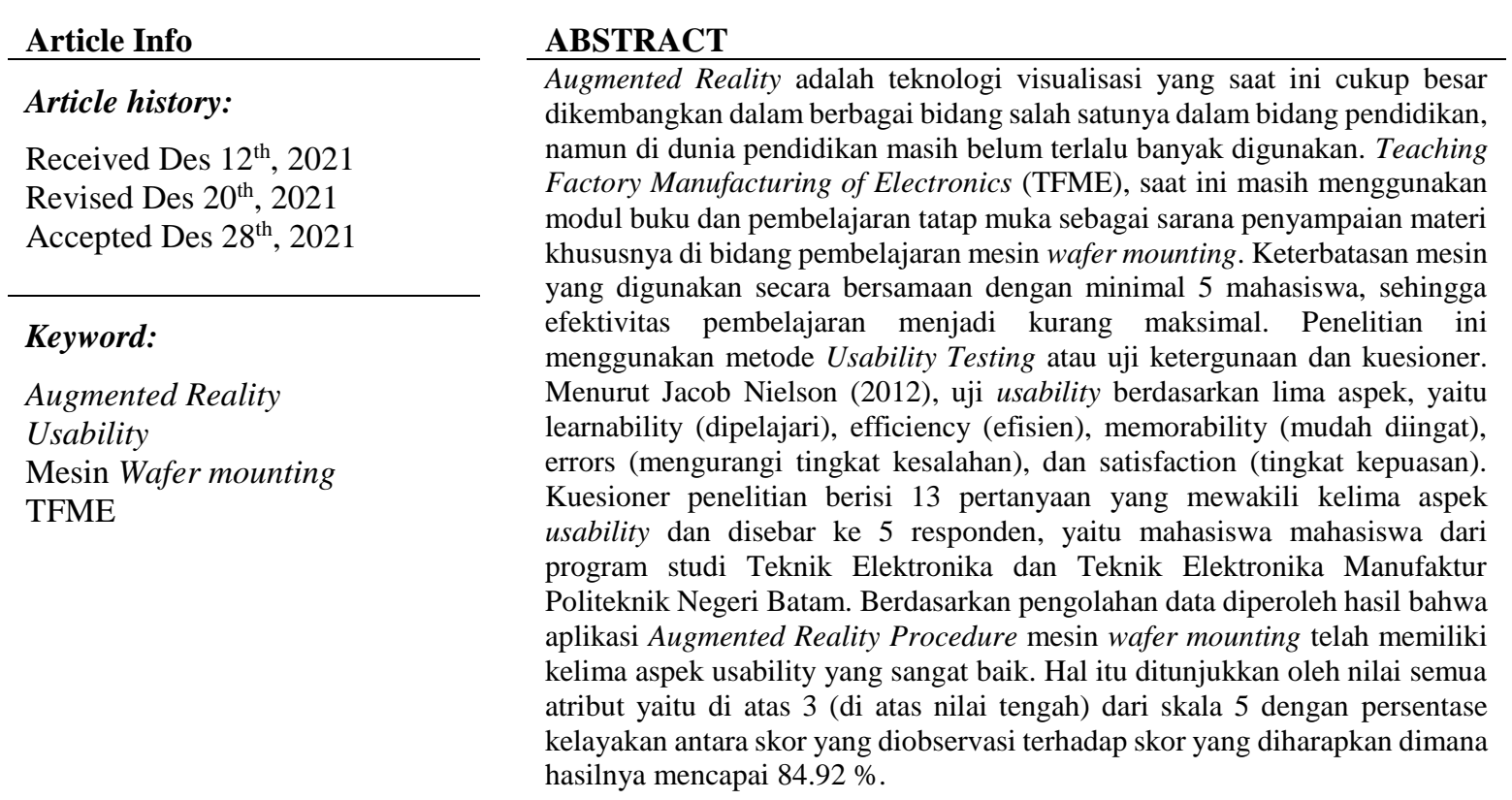

\section{PENDAHULUAN}

Perkembangan teknologi yang sangat pesat di zaman ini membawa dampak yang relevan untuk berbagai jenis teknologi dan penemuan baru sebagai solusi untuk mengatasi berbagai permasalahan kehidupan. Hal inilah yang membuat manusia membutuhkan sebuah media yang dapat digunakan untuk menyelesaikan masalah dengan cepat dan efisien di segala bidang, salah satu contoh adalah teknologi Augmented Reality [1].

Seiring dengan Augmented Reality yang terus berkembang. Sebagai contoh pada periklanan, perusahaan Nissan, Toyota, BMW, dan Mini menggunakan iklan majalah dan AR untuk memberi penampilan tampilan 3D penuh dari mobil yang dilakukan, Rumah dan Industri, Total Immersion's Magic Mirror menggunakan Augmented Reality untuk menempatkan dan menskalakan representasi furniture atau perkakas sehingga pengguna dapat merasakan tampilannya, Seni, Museum Seni Modern New York 2010 menyelenggarakan pameran yang memugkinkan siapa saja yang memiliki smartphone dapat melihat pameran "tersembunyi" di Augmented Reality sehingga membuat pameran lebih menarik dan inovatif, hiburan dan Game Industri ada juga kamera di Drone yang memungkinkan pengguna melihat sesuatu dari sudut pandang Drone dan memungkinkan pengguna untuk memilikinya pertarungan virtual dengan Drone lainnya [2]. AR juga banyak digunakan dalam berbagai bidang, missal pendidikan, industri, game, dsb. Secara umum AR digunakan untuk pengenalan objek atau lokasi secara virtual [1]. 
Sudah banyak lembaga pendidikan yang menggunakan teknologi Augmented Reality (AR), salah satunya di Teaching Factory Manufacturing of Electronics (TFME) Polibatam. TFME polibatam merupakan salah satu unit yang memproduksi IC dalam sekala terbatas yang digabungkan dalam proses kuliah yang di sebut dengan Teaching Factory [3]. Dalam aktifitasnya TFME mempunyai hambatan salah satunya adalah keterbatasan mesin wafer mounting dimana satu alat dipakai secara bersamaan minimal 5 mahasiswa sehingga efektivitas pembelajaran menjadi kurang maksimal. Untuk memecahkan persoalan tersebut solusinya adalah menggunakan aplikasi Augmented Reality sebagai media untuk pembelajaran sistem mesin Wafer mounting. Penggunaan aplikasi Augmented Reality sudah berkembang sangat pesat sehingga memungkinkan pengembangan aplikasi ini di berbagai bidang termasuk pendidikan tinggi [1]. Tujuan aplikasi ini sebagai alternatif media pembelajaran yang lebih menarik dan termotivasi, dan mahasiswa bisa belajar dimanapun tanpa mengharuskan untuk datang ke lokasi laboratorium.

Terkait dengan aplikasi Augmented Reality mesin wafer mounting adalah suatu produk multimedia interaktif dimana di dalam aplikasi terdapat video materi terkait penjelasan materi mesin wafer mounting. Produk tersebut dibuat agar memudahkan para mahasiswa dalam memahami proses prosedur pada mesin wafer mounting yang digunakan oleh mahasiswa dari Teknik Elektronika dan Teknik Elektronika Manufaktur.

Faktor penentu keberhasilan untuk setiap aplikasi perangkat lunak dan beberapa metode evaluasinya adalah menggunakan usability [4]. Tujuan pengujian usability dilakukan untuk mengevaluasi apakah sebuah aplikasi sudah sesuai dengan kebutuhan pengguna [5].

Oleh karena itu, penulis membuat suatu penelitian yaitu "Analisis Usability Aplikasi AR Procedure Mesin Wafer mounting Di Teaching Factory Manufacture Of Electronics (TFME) Politeknik Negeri Batam". Hasil dari penelitian ini diharapkan bisa memberi masukan untuk pengembangan selanjutnya agar usability pada sistem dapat ditingkatkan.

\section{Landasan Teori dan Tinjauan Pustaka}

\subsection{Dasar Teori}

\subsubsection{Augmented Reality}

Usability Augmented Reality (AR) adalah bagian dari Environment Reality (ER) atau yang disebut dengan Virtual Reality (VR). VR menjadi salah satu teknologi yang menggabungkan benda maya dua dimensi dengan tiga dimensi ke dalam sebuah lingkungan nyata lalu mengubah bendabenda maya tersebut dalam waktu nyata. Fungsi dari benda-benda maya sebagai objek untuk memperlihatkan informasi yang tidak dapat diterima oleh manusia secara langsung. Maka dari itu realitas tertambah berperan sebagai alat untuk membantu persepsi dan interaksi penggunanya dengan dunia nyata. Penjelasan pada informasi yang diperlihatkan oleh benda maya membantu pengguna melaksanakan kegiatan aktivitas dalam dunia nyata [6].

\subsubsection{Teaching Factory Manufacture of Elecgronics (TFME)}

Salah satu keunggulan yang dimiliki Politeknik Negeri Batam, yaitu memiliki fasilitas laboratorium Teaching Factory of Micro Electronics yang tidak banyak dimiliki oleh PTN lain di Indonesia. Teaching factory manufacturing of electronics (TFME) Polibatam merupakan sebuah laboratorium polibatam yang memproduksi IC dalam skala terbatas dan fokus pada bidang Elektronik Mikro yang menghasilkan produk seperti IC packaging, PCB manufacturing dan PCB assembly. Laboratorium ini digabungankan dalam proses pembelajaran kuliah yang disebut Teaching Factory. Laboratorium tersebut diresmikan pada tahun 2016 dan menjadi salah satu satu laboratorium di Indonesia yang fokus pada bidang keilmuan Elektronik Mikro yang menghasilkan produk komersial seperti IC packaging dan PCB hingga 6 layer. Berbagai perusahaan besar baik lokal ataupun asing seperti Philips dan Polytron telah melakukan kerja sama dengan memesan PCB untuk beberapa barang elektronik. Dengan adanya laboratorium Teaching Factory menjadi salah satu bukti tujuan Polibatam dalam mewujudkan sistem pembelajaran vokasi berbasis kompetensi, bermutu dan relevan [3].

\subsubsection{Augmented Reality Mesin Wafer mounting}

Augmented Reality Mesin Wafer mounting adalah suatu aplikasi Augmented reality yang digunakan sebagai media untuk pembelajaran pada mesin wafer mounting yang ada di Teaching 
Factory Manufacturing of Electronics (TFME), dimana di dalam aplikasi terdapat materi video terkait penjelasan proses mesin wafer mounting. Aplikasi tersebut dibuat agar memudahkan mahasiswa dalam memahami pengoperasian tahapan proses mesin wafer mounting seperti pada gambar dibawah ini.

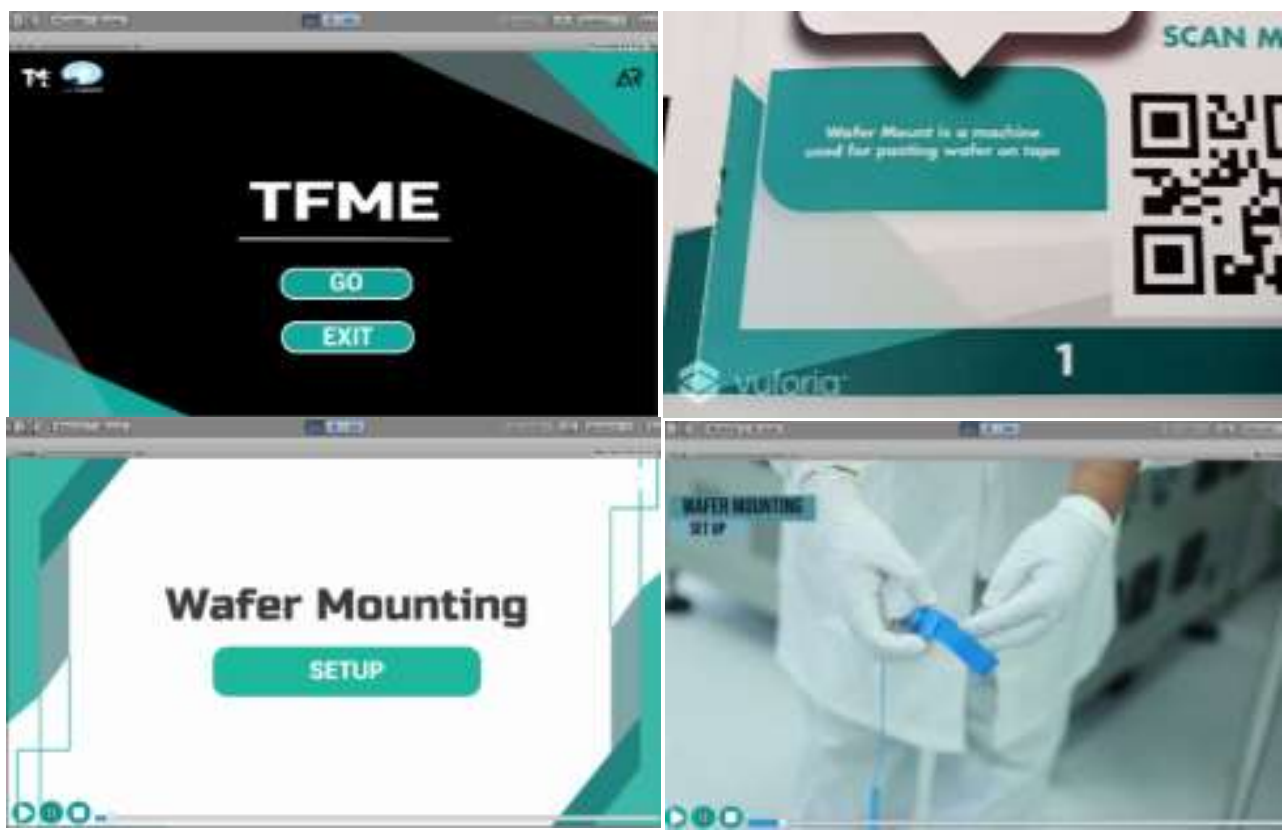

Gambar 1. User interface aplikasi wafer mounting

\subsubsection{Mesin Wafer mounting}

Mesin wafer mounting adalah mesin yang digunakan untuk menempel wafer diatas blue tape sehingga bisa di proses ke tahap selanjutnya. Hal ini bertujuan agar wafer dapat dipegang dan saat wafer berada pada proses dicing, die tidak berantakan. Gambar mesin wafer mounting bisa di lihat pada gambar 2.

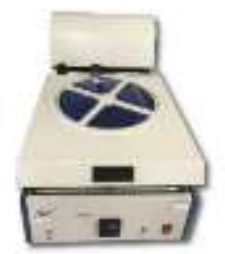

\subsubsection{QR-Code}

Gambar 2. Mesin Wafer mounting

Quick Response Code (QR-Code) adalah gambar berupa matriks dua dimensi yang dapat dibaca oleh telepon pintar dan ponsel dengan kamera. $Q R$ Code merupakan evolusi dari kode batang (barcode) [6]. QR-Code memiliki fungsi atau tujuan adalah penyampaian informasi dengan cepat dan mendapat tanggapan atau respon yang cepat. Oleh karena itu $Q R$-Code dapat dengan mudah dibaca oleh pemindai. Gambar QR-Code Mesin Wafer mounting dapat dilihat pada gambar 3.

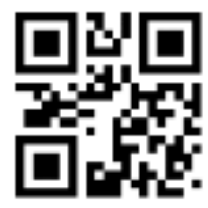

Gambar 3. Gambar QR-Code Mesin Wafer mounting 


\subsubsection{Populasi dan Sampel}

Populasi merupakan seluruh jumlah dari subjek yang akan diteliti oleh seorang peneliti. Sedangkan sampel merupakan bagian dari jumlah dan karakteristik yang dimiliki oleh suatu populasi. Teknik sampling adalah teknik yang dilakukan untuk menentukan sampel. Teknik sampling yang digunakan adalah purposive sampling. Teknik purposive sampling adalah teknik penentuan sampel yang didasarkan pada pertimbangan peneliti mengenai sampel-sampel mana yang paling sesuai, bermanfaat dan dianggap dapat mewakili suatu populasi (representatif). Teknik pengambilan sampel ini cenderung lebih tinggi kualitas sampelnya karena telah membuat batas berdasarkan kriteria [7].

\subsubsection{Usability}

Usability bermula dari kata Usable yang secara umum berarti dapat digunakan dengan baik. Sesuatu yang dapat dikatakan berguna dengan baik adalah pada saat kegagalan dalam penggunaanya dapat dihilangkan atau diminimalkan serta memberi manfaat dan kepuasan kepada pengguna [8].

\subsection{Usability Testing}

Dasar dari penilaian usability adalah pengalaman yang dirasakan pengguna ketika menggunakan aplikasi tersebut [7]. Berikut ini beberapa komponen kualitas:

1. Learnabilitas (Learnability)

Mengukur kemudahan yang dapat dipelajari bahkan oleh pengguna pemula dalam menggunakan sebuah produk untuk pertama kali.

2. Efisiensi (Efficiency)

Mengukur seberapa cepat pengguna dapat melakukan tugasnya setelah mempelajarai antarmuka guna mencapai ketepatan dan kelengkapan tujuan.

3. Memorabilitas (Memorability)

Apakah aplikasi yang telah lama tidak digunakan ataupun aplikasi yang baru digunakan 1 kali dapat diingat oleh pengguna.

4. Kesalahan (Errors)

Semakin kecil tingkat kesalahan maka semakin baik aplikasi tersebut. Aplikasi tersebut dapat dilihat dari berapa banyak kesalahan yang terjadi saat pengguna menggunakan aplikasi, sejauh mana akibat dari error tersebut, dan seberapa mudah seorang pengguna mengatasi kesalahan yang dilakukannya.

5. Kepuasan (Satisfaction)

Kepuasan bersifat subjektif bagi masing-masing pengguna yang meliputi perasaan saat menggunakan aplikasi, pendapatnya tentang aplikasi tersebut dan lain-lain.

\subsubsection{Pengukuran Usability dengan Use Questioner}

USE Questionnaire merupakan bentuk kuesioner untuk membantu dalam pengukuran usability produk maupun jasa secara subjektif daya gunanya yang terdiri dari 13 pertanyaan yang dikelompokkan ke dalam 5 parameter, diantaranya: Learnability, Efficiency, Memorability, Errors dan Satisfaction. Kuesioner dibuat dalam bentuk skor lima point dengan model skala likert untuk pengukuran tingkat persetujuan user terhadap statement hasil pengukuran kemudian diolah dengan metoda statistik deskriptif dan dilakukan analisis baik terhadap masing-masing parameter atau terhadap keseluruhan parameter. Use merupakan salah satu paket kuesioner non komersial yang dapat digunakan untuk penelitian usability system [9].

\section{Metode Penelitian}

\subsection{Analisis Perancangan}

Metode penelitian yang digunakan dalam penelitian ini adalah pengujian usability mengguakan USE Questionnaire. Usability adalah atribut kualitas yang digunakan untuk mengetahui bagaimana user interface digunakan [10]. Tahapan penelitian dimulai mengidentifikasi masalah, dilanjutkan dengan melakukan studi awal, yaitu studi literatur/studi pustaka yang berhubungan dengan pengujian kebergunaan (usability testing) dan juga studi terhadap objek yang akan diamati, kemudian mengambil kesimpulan dari hasil analisa data tersebut [11]. Gambar 4 merupakan gambar dari tahapan penelitian. 


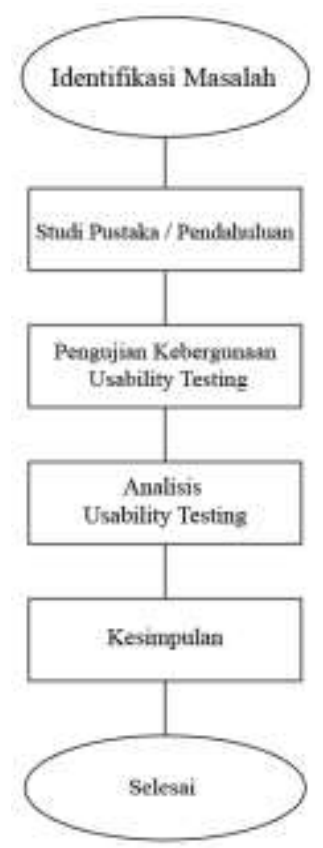

Gambar 4. Alur Pengujian Usability

Pada pengujian aspek usability, analisis data dilakukan cara menghitung rata-rata jawaban berdasarkan skoring setiap jawaban dari kuesioner yang diisi responden. Kriteria penilaian untuk instrumen usability menggunakan skala likert dengan memberikan lima pilihan jawaban seperti yang ditunjukkkan pada tabel 1 .

Tabel 1. Interval Skala Likert

\begin{tabular}{|c|c|}
\hline Alternatif Jawaban & Nilai \\
\hline Sangat Tidak Setuju & 1 \\
\hline Tidak Setuju & 2 \\
\hline Ragu-Ragu & 3 \\
\hline Setuju & 4 \\
\hline Sangat Setuju & 5 \\
\hline
\end{tabular}

Setelah mendapat jumlah skor dihitung persentase kelayakan pengukuran usability dilakukan dengan menghitung persentase jawaban dari responden menggunakan rumus yang dinyatakan dalam [12].

$$
\text { Persentase Kelayakan }(\%)=\frac{\text { Skor yang diobservasi }}{\text { Skor yang diharapkan }} \times 100 \%
$$

Penilaian dikatakan layak jika rata-rata dari penilaian dalam kriteria baik. hasil persentase, dibandingkan dengan tabel kriteria interprestasi skor. Persentase nilai dapat dilihat pada tabel 2.

Tabel 2. Persentase Nilai Imterprestasi Skor Setelah Dikonversi

\begin{tabular}{|c|c|}
\hline Angka (dalam \%) & Klasifikasi \\
\hline $0-20$ & Sangat Tidak Setuju \\
\hline $21-40$ & Tidak Setuju \\
\hline $41-60$ & Ragu-Ragu \\
\hline $61-80$ & Setuju \\
\hline
\end{tabular}




\begin{tabular}{|l|l|}
\hline $81-100$ & Sangat Setuju \\
\hline
\end{tabular}

\section{HASIL ANALISIS DAN PEMBAHASAN}

\subsection{Hasil Analisa Usability}

\subsubsection{Pengujian Alpha}

Pada pengujian Alpha dengan menggunakan teknik black box, pengujian dilakukan untuk memastikan apakah aplikasi dapat berjalan dengan baik pada sistem operasi dari user atau pengguna aplikasi [13]. Berikut adalah hasil pengujian alpha pada aplikasi Augmented Reality mesin Wafer mounting. hasil pengujian alpha pada aplikasi Augmented Reality mesin Wafer mounting dapat dilihat pada tabel 3 .

Tabel 3. Hasil Pengujian Black Box Testing aplikasi Augmented Reality mesin Wafer mounting

\begin{tabular}{|c|c|c|c|c|}
\hline \multirow[t]{2}{*}{ No } & \multirow{2}{*}{$\begin{array}{l}\text { Komponen } \\
\text { yang Diuji }\end{array}$} & \multicolumn{3}{|c|}{ Skenario dan Hasil Uji } \\
\hline & & Tampilan Aplikasi & Hasil Diharapkan & Kesimpulan \\
\hline 1 & $\begin{array}{c}\text { Halaman } \\
\text { Menu } \\
\text { Utama }\end{array}$ & $\frac{\text { TFME }}{\text { करा }_{\text {का }}}$ & $\begin{array}{l}\text { Aplikasi menampilkan } \\
\text { menu utama yang terdiri } \\
\text { dari } 2 \text { button yaitu Button } \\
\text { Go dan Button Exit. }\end{array}$ & $\begin{array}{l}\text { [ } \sqrt{\text { ] Berhasil }} \\
\text { [ ] Tidak Berhasil }\end{array}$ \\
\hline 2 & $\begin{array}{c}\text { Halaman } \\
\text { Kamera }\end{array}$ & & $\begin{array}{l}\text { Aplikasi menampilkan } \\
\text { halaman kamera yang } \\
\text { berfungsi untuk mendeteksi } \\
Q R \text {-code. }\end{array}$ & $\begin{array}{l}{[\sqrt{]} \text { Berhasil }} \\
\text { [ ] Tidak Berhasil }\end{array}$ \\
\hline 3 & $\begin{array}{c}\text { Halaman } \\
\text { Video }\end{array}$ & & $\begin{array}{l}\text { Aplikasi menampilkan } \\
\text { halaman video setelah } \\
\text { berhasil mendeteksi } Q R \text { - } \\
\text { code. }\end{array}$ & $\begin{array}{l}{[\sqrt{ }] \text { Berhasil }} \\
\text { [ ] Tidak Berhasil }\end{array}$ \\
\hline
\end{tabular}

Berdasarkan hasil pengujian, maka didapat kesimpulan bahwa aplikasi dapat berjalan sesuai harapan, dimana fitur maupun fungsi dari setiap menu maupun QR-Code yang ada berfungsi dengan baik dan sesuai dengan tujuan pengujian dan dapat digunakan sebagai media pembelajran mesin TFME.

\subsubsection{Pengujian Beta}

Pengujian beta dimulai dari memberikan kuesioner dengan 13 pertanyaan yang sudah mewakili kelima aspek usability dan akan diserahkan kepada 5 mahasiswa dari Program Studi Teknik Elektronika dan Teknik Elektronika Manufaktur. Tiap-tiap pertanyaan dari kuesioner tersebut bertujuan untuk menunjukkan tingkat usability menurut penerimaan user dengan menggunakan skala likert dari skala 1 sampai 5. Berikut adalah hasil pengujian beta pada terhadap hasil kuesioner yang diperoleh pada aplikasi Augmented Reality mesin Wafer mounting dapat dilihat pada tabel 4.

Tabel 4. Presentase Jawaban Responden

\begin{tabular}{|c|c|c|c|c|c|c|c|}
\hline \multirow[t]{2}{*}{ No } & \multirow[t]{2}{*}{ Pertanyaan } & \multicolumn{5}{|c|}{ Jawaban } & \multirow[t]{2}{*}{ HASIL } \\
\hline & & STS & TS & $\mathrm{R}$ & $\mathrm{S}$ & SS & \\
\hline \multicolumn{8}{|c|}{ Learnability } \\
\hline 1 & $\begin{array}{l}\text { Apakah tampilan menu dalam } \\
\text { aplikasi AR mesin Wafer mounting } \\
\text { mudah untuk dikenali? }\end{array}$ & 0 & 0 & 0 & 4 & 1 & $84 \%$ \\
\hline 2 & $\begin{array}{l}\text { Apakah informasi yang disediakan } \\
\text { oleh aplikasi AR mesin Wafer } \\
\text { mounting ini mudah dimengerti? }\end{array}$ & 0 & 0 & 0 & 5 & 0 & $80 \%$ \\
\hline
\end{tabular}




\begin{tabular}{|c|c|c|c|c|c|c|c|}
\hline 3 & $\begin{array}{l}\text { Apakah penggunaan menu atau fitur } \\
\text { aplikasi AR mesin Wafer mounting } \\
\text { mudah digunakan? }\end{array}$ & 0 & 0 & 0 & 2 & 3 & $92 \%$ \\
\hline \multicolumn{7}{|c|}{ Total } & $85.3 \%$ \\
\hline \multicolumn{8}{|c|}{ Efficiency } \\
\hline 4 & $\begin{array}{l}\text { Apakah aplikasi AR mesin Wafer } \\
\text { mounting dapat dengan cepat saat } \\
\text { dioprasikan? }\end{array}$ & 0 & 0 & 1 & 3 & 1 & $80 \%$ \\
\hline 5 & $\begin{array}{l}\text { Apakah aplikasi AR mesin Wafer } \\
\text { mounting dapat dengan cepat } \\
\text { dipelajari? }\end{array}$ & 0 & 0 & 0 & 2 & 3 & $92 \%$ \\
\hline \multicolumn{7}{|c|}{ Total } & $86 \%$ \\
\hline \multicolumn{8}{|c|}{ Memorability } \\
\hline 6 & $\begin{array}{l}\text { Apakah aplikasi AR mesin Wafer } \\
\text { mounting memiliki menu dan } \\
\text { tampilan yang mudah diingat? }\end{array}$ & 0 & 0 & 0 & 2 & 3 & $92 \%$ \\
\hline 7 & $\begin{array}{l}\text { Apakah aplikasi AR mesin Wafer } \\
\text { mounting ini nyaman digunakan? }\end{array}$ & 0 & 0 & 0 & 3 & 2 & $88 \%$ \\
\hline 8 & $\begin{array}{l}\text { Apakah informasi yang diberikan } \\
\text { aplikasi AR mesin Wafer mounting } \\
\text { sangat jelas? }\end{array}$ & 0 & 0 & 0 & 4 & 1 & $84 \%$ \\
\hline \multicolumn{7}{|c|}{ Total } & $88 \%$ \\
\hline \multicolumn{8}{|c|}{ Error } \\
\hline 9 & $\begin{array}{l}\text { Apakah dapat dengan mudah } \\
\text { menghindari kesalahan dalam } \\
\text { menggunakan aplikasi AR mesin } \\
\text { Wafer mounting? }\end{array}$ & 0 & 0 & 2 & 1 & 2 & $80 \%$ \\
\hline 10 & $\begin{array}{l}\text { Apakah aplikasi AR mesin Wafer } \\
\text { mounting mempunyai kemampuan } \\
\text { dan fungsi yang diharapkan? }\end{array}$ & 0 & 0 & 2 & 1 & 2 & $80 \%$ \\
\hline \multicolumn{7}{|c|}{ Total } & $80 \%$ \\
\hline \multicolumn{8}{|c|}{ Satisfaction } \\
\hline 11 & $\begin{array}{l}\text { Apakah secara keseluruhan } \\
\text { penggunaan aplikasi AR mesin } \\
\text { Wafer mounting ini memuaskan? }\end{array}$ & 0 & 0 & 0 & 4 & 1 & $84 \%$ \\
\hline 12 & $\begin{array}{l}\text { Apakah aplikasi AR mesin Wafer } \\
\text { mounting ini sesuai dengan } \\
\text { kebutuhan? }\end{array}$ & 0 & 0 & 0 & 3 & 2 & $88 \%$ \\
\hline 13 & $\begin{array}{l}\text { Apakah aplikasi AR mesin Wafer } \\
\text { mounting sangat bermanfaat bagi } \\
\text { pengguna? }\end{array}$ & 0 & 0 & 0 & 5 & 0 & $80 \%$ \\
\hline \multicolumn{7}{|c|}{ Total } & $84 \%$ \\
\hline \multicolumn{2}{|c|}{ Total Keseluruhan } & \multicolumn{5}{|c|}{276} & $84.92 \%$ \\
\hline
\end{tabular}

Untuk menghitung setiap jawaban dari responden penulis menggunakan skala likert, dengan rumus yang dijelaskan sebagai berikut:

Nilai total yang didapat adalah 276, sedangkan nilai maksimal untuk tiap pernyataan adalah 5 (Sangat Setuju), sehingga dapat diperoleh nilai total maksimal adalah 325. Nilai maksimal tersebut diperoleh dari hasil perkalian jumlah responden, jumlah pertanyaan, dan nilai maksimal tiap pernyataan yaitu $5 \times 13 \mathrm{x}$ $5=325$. Setelah menentukan nilai maksimal, maka untuk persentase kelayakan usability secara keseluruhan adalah sebagai berikut:

Persentase Kelayakan $(\%)=\underline{\text { Skor yang diobservasi }} \times 100 \%$

$$
\begin{aligned}
& \text { Skor yang diharapkan } \\
= & \frac{276}{325} \times 100 \%=84.92 \%
\end{aligned}
$$

Berdasarkan hasil observasi maka dapat pembelajaran mesin wafer mounting menggunakan aplikasi Augmented Reality memenuhi standar usability, yakni sebesar $84.92 \%$ dan mendapatkan kelayakan Sangat Baik (SB). 


\subsection{Hasil Analisis Pengujian Data Kuesioner}

Pengukuran usability yang dilakukan terdiri dari 5 aspek sesuai dengan hasil penelusuran data dengan menggunakan angket yaitu, Learnability, Efficiency, Memorability, Error, Satisfaction.

Berdasarkah hasil persentase setiap pertanyaan yang didapatkan sesuai dengan tabel pengujian beta yang dilakukan kepada responden. Perhitungan penilaian Tingkat Ketergunaan (Usability) dapat dilihat pada tabel 5.

Tabel 5. Hasil Pengukuran Aspek Usability

\begin{tabular}{|l|c|c|}
\hline \multicolumn{1}{|c|}{ Pernyataan } & Pencapaian\% & Kriteria \\
\hline Learnability & $85.3 \%$ & Sangat Baik \\
\hline Efficiency & $86 \%$ & Sangat Baik \\
\hline Memorability & $88 \%$ & Sangat Baik \\
\hline Error & $80 \%$ & Baik \\
\hline Satisfaction & $84 \%$ & Sangat Baik \\
\hline
\end{tabular}

Berdasarkan hasil pengujian yang telah dilakukan analisis dari aplikasi Augmented Reality mesin Wafer mounting bahwa setiap responden tentang kualitas berdasarkan kelima aspek (Learnability, Efficiency, Memorability, Error, Satisfaction) dari responden didapatkan hasil yang sangat baik. Persentase tersebut memberikan arti bahwa responden memberikan penilaian pada aplikasi Augmented Reality mesin Wafer mounting sangat berkualitas. Hasil analisa juga menunjukkan bahwa tidak ada aspek yang perlu dilakukan perbaikan, hanya saja perlu adanya edukasi pembelajaran dalam penggunaan aplikasi Augmented Reality untuk menghindari permasalahan yang ada yaitu saat pengguna belum terbiasa memakai metode pembelajaran yang lebih interaktif. Sesuatu bisa dikatakan berfungsi dengan baik apabila kegagalan dalam penggunaannya bisa diminimalisir bahkan dihindarkan untuk tercapainya tujuan yang efisien dan efektif dalam penggunannya yang dapat memberikan kepuasan kepada pengguna. Secara umum usability merupakan suatu tanda dari kualitas yang akan dipergunakan dengan baik [8].

\section{KESIMPULAN DAN SARAN}

\subsection{Kesimpulan}

Berdasarkan hasil analisis data yang telah dilakukan dapat diambil kesimpulan sebagai berikut:

1. Hasil dari proses olahan data diatas analisis usability berdasarkan lima parameter serta rekomendasi untuk penyempurnaan aplikasi Augmented Reality Mesin Wafer mounting. Berdasarkan hasil observasi maka pembelajaran materi mesin Wafer mounting menggunakan aplikasi Augmented Reality memenuhi standar usability, yakni sebesar $84.92 \%$ dan mendapatkan kelayakan sangat baik sehingga dapat diterapkan sebagai aplikasi yang dapat dioperasikan oleh mahasiswa Program Studi Teknik Elektronika dan Teknik Elektronika Manufaktur

2. Dari kelima parameter, 4 kriteria yaitu Learnability, Efficiency, Memorability dan Satisfaction mengindikasikan bahwa sistem mudah dipelajari mendapat nilai $85.3 \%$, efisien dalam operasinya mendapat nilai $86 \%$, fungsi dan fitur dapat diingat mendapat nilai $88 \%$, dan pengguna cukup puas dalam menggunakan sistem $84 \%$. Kriteria Error mendapat nilai $80 \%$ disebabkan mahasiswa belum terbiasa menggunakan aplikasi Augmented Reality.

\subsection{Saran}

Berdasarkan kesimpulan di atas, maka penulis memberikan saran-saran sebagai berikut, yaitu:

1. Bagi peneliti selanjutnya disarankan untuk mengkaji lebih dalam pada masing - masing faktor yang sudah dijabarkan dalam penelitian ini untuk menjadi lebih baik terutama pada aspek Error mendapat nilai rata-rata yang lebih rendah di bandingkan dengan aspek lainnya. Saran ini diberikan agar pengembang selanjutnya bisa memperhatikan aspek tersebut untuk penelitian selanjutnya.

2. Peneliti dapat memperbanyak dan memperluas cakupan artikel yang digunakan dalam penelitian dan melakukan metode yang serupa dengan penelitian ini, namun menggunakan objek mesin yang berbeda misalnya pada bagian mesin IC Packaging, PCB Manufacturing, dan PCB Assembly. 


\section{DAFTAR PUSTAKA}

[1] Aelani, K., \& Falahah. (2012). Pengukuran Usability Sistem Menggunakan Use Questionnaire (Studi Kasus Aplikasi Perwalian Online STMIK "AMIKBANDUNG"). Seminar Internasional Aplikasi Teknologi Informasi, 6.

[2] Arista, P. D. (2016). Pengembangan Brosur Interaktif “Aryappi” Berbasis Augmented Reality Sebagai Media Iklan Smk Yappi Wonosari. Skripsi, 155.

[3] Kipper, G. \& Joseph Rampolla, 2013. Augmented Reality. First Edition ed. USA: British Library.

[4] Masripah, S., \& Ramayant, L. (2020). Penerapan Pengujian Alpha Dan Beta Pada Aplikasi Penerimaan Siswa Baru . Jurnal Swabumi, 6.

[5] Nurhadryani, Y., Sianturi, S. K., Hermadi, I., \& Khotimah, H. (n.d.). Pengujian Usability untuk Meningkatkan Antarmuka Aplikasi . ilmu komputer agri-informatika, 11.

[6] Oktavia, c. a., setiawan, r. f. \& Christianto, A., 2019. Perancangan Aplikasi Augmented Reality Untuk Pengenalan ruangan menggunakan marker 3D Objects tracking. Jurnal Ilmiah Teknologi Informasi Asia, XX(2580-8397), p. 12.
[7] Polibatam,
H., $2018 . \quad$ Teachin
Factory
Polibatam.
[Online]

Available at: https://www.polibatam.ac.id/teaching-factory-polibatam/. [Accessed 9 November 2020].

[8] P. Istiana, "Evaluasi Usability Situs Web Perpustakaan," VISI PUSTAKA, vol. 13, no. 3, pp. 5- 10, 2011.

[9] Rahadi, D. R., 2014. Pengukuran Usability Sistem Menggunakan Use Questionnaire Pada Aplikasi Android. Jurnal Sistem Informas, 6(2355-4614), p. 11.

[10] Rubin, j., \& chisnell, d. (2011). Handbook of Usability Testing. komputer, 384.

[11] Resmiati, r., Febryan, R., Pertiwi, T.W., \& Febrilla, F. (n.d). Uji Usability Mobile App Cinema21 Menggunakan. Sistem informasi, 6.

[12] Susanti, E., Iswahyudi, C., Romadhani3, T., Wahyuningsih, S., \& Putra5, F. T. (2018). Pemanfaatan Teknologi Quick Response (Qr) Code Pada Sistem Manajemen Studi Ekskursi. Simposium Nasional, 9.

[13] Sugiyono. (2016). Metode Penelitian Kuantitatif, Kualitatif dan R\&D. Bandung: PT Alfabet. 